\title{
Population-level investigation of the knowledge of ocular chemical injuries and proper immediate action
}

Hadeel Seraj ( $\sim$ Hadeel.Seraj@gmail.com )

https://orcid.org/0000-0001-7461-1128

Shahad Khawandanh

King Abdulaziz University

Arwa Fatani

King Abdulaziz University

Afnan Saeed

King Abdulaziz University

Ghadeer Alotaibi

King Abdulaziz University

Ahmed Basheikh

King Abdulaziz University

\section{Research note}

Keywords: Eye damage, Saudi Arabia, corrective steps, alkaline, acidic

Posted Date: January 2nd, 2020

DOI: https://doi.org/10.21203/rs.2.19532/v1

License: (c) (1) This work is licensed under a Creative Commons Attribution 4.0 International License. Read Full License

Version of Record: A version of this preprint was published at BMC Research Notes on February 25th, 2020. See the published version at https://doi.org/10.1186/s13104-020-04950-5. 


\section{Abstract}

Objective: Although the eyes occupy $0.1 \%$ of the total body surface, eye injuries are serious because vision is arguably the most important sense. We aimed to assess knowledge of Saudi Arabian residents regarding steps to be taken in cases of chemical eye injury, in order to promote awareness of such procedures.

Results: This study included 888 individuals in the Saudi community; most of them were female (624, $70.3 \%)$, and 359 (40.4\%) respondents were 18-29 years of age. Regarding the first step taken in case of chemical eye injury, 697 (78.5\%) respondents indicated washing with water, 164 (18.5\%) indicated visiting the emergency department, $11(1.2 \%)$ indicated using eye drops, and $5(0.6 \%)$ indicated covering the eye immediately. A total of 491 (55.3\%) respondents agreed that alkaline injuries were more dangerous than acidic injuries. Seventy-five (8.4\%) respondents agreed that an eye injured with an acidic material should be washed with an alkaline solution, while 60 (6.8\%) respondents agreed that an eye exposed to an alkaline material should be washed with an acidic solution. These results should be confirmed by health authorities and appropriate interventions should be developed for improving perception and knowledge among masses, thereby promoting a healthier society.

\section{Introduction}

The eyes occupy $0.1 \%$ of the total body surface and $0.27 \%$ of the anterior body surface; however, the seriousness of ocular injury is amplified relative to these proportions, as vision is arguably the most important sense. Loss of vision may affect quality of life because it can lead to job loss, dramatic lifestyle changes, and facial deformities [1, 2]. Ocular injuries place a high burden on the community and are generally preventable [3]. Chemical injuries can involve alkaline and acidic injuries. Alkaline burns are more common, due to the widespread use of alkaline substances in industrial and home cleaning products; these burns typically result in more severe injuries [4]. Approximately $7 \%$ of work-related eye injuries treated in hospital emergency departments in the United States are related to chemical injuries [5]. Additionally, more than $60 \%$ of chemical injuries occur in workplace accidents, $30 \%$ occur at home, and $10 \%$ are the result of an accident [6]. Up to $20 \%$ of chemical injuries result in massive visual disability and facial disfigurement; notably, visual rehabilitation after an advanced chemical eye injury occurs in less than $15 \%$ of the affected individuals $[5,6]$. Men are 3 -fold more likely to experience chemical injuries than women; furthermore, individuals aged 16-45 years are most likely to be affected [6].

In Saudi Arabia, a prior study reviewed the data regarding local chemical injuries in two major government hospitals. Among a total of 59 patients (3:1, male:female ratio; mean age, 25 years), alkaline drain cleaners were the most common cause of chemical burns (75\% of the patients). In remaining patients, causes comprised concentrated sulfuric acid, car battery acid, and topical application of herbs [7]. Familiarity with various types of ocular and periocular injuries is important for all community members, particularly those with high risk of such injuries. To our knowledge, there have been no investigations about knowledge of chemical eye injury and appropriate immediate action in the general 
population of Saudi Arabia. Thus, we aimed to assess knowledge in the Saudi population regarding the first corrective action after chemical eye injury, in order to increase awareness of such injuries and to support a healthier society.

\section{Material And Methods}

A cross-sectional study was conducted among individuals in the Saudi community during November 2018. Data were collected by using a self-administered electronic questionnaire, which was disseminated through social media.

The study included both men and women $\geq 18$ years of age. Ethical approval was obtained from the Biomedical Ethics Committee at King Abdulaziz University (Jeddah, Saudi Arabia). The sample size was determined by using a sample size calculator site (http://www.raosoft.com/samplesize.html); the minimum recommended sample size was 377, and we included 888 respondents. It consisted of 2 parts: the first part acquired demographic data (age, sex, marital status, educational degree, and job); the second part assessed knowledge of ocular chemical injuries and the proper immediate action. Data entry and statistical analysis were performed using IBM SPSS Statistics for Windows, Version 21.0. (IBM Corp., Armonk, NY, USA). Frequency and percentages were used to describe categorical variables, while mean (standard deviation) was used to describe continuous numerical variables. P-values of $<0.05$ were considered to be statistically significant.

\section{Results}

Demographic Information

This study included 888 individuals in the Saudi community during November 2018. Most of them were female $(624,70.3 \%)$. An additional table file shows this in more detail (see Additional file 1).

Table 1

Age characteristics of the respondents

\begin{tabular}{|lll|}
\hline & Frequency & Percent \\
\hline $18-29$ & 359 & 40.4 \\
\hline $30-39$ & 207 & 23.3 \\
$40-49$ & 150 & 16.9 \\
\hline 50 or more & 172 & 19.4 \\
\hline Total & 888 & 100.0 \\
\hline
\end{tabular}

Age distribution of the respondents is shown with the majority aged $18-29$ years $(359,40.4 \%)$ (Table 1$)$. 
Regarding education level among the respondents, most $(575,64.8 \%)$ had a bachelor's degree. An additional table file shows this in more detail (see Additional file 2).

Regarding jobs among the respondents, 234 (26.4\%) were students, and 249 (28.0\%) worked in the government sector, while 215 (24.2\%) were homemakers or unemployed. An additional table file shows this in more detail (see Additional file 3).

Regarding type of job among the respondents, 286 (32.2\%) had an office job, and 160 (18.0\%) worked in the medical field. An additional table file shows this in more detail (see Additional file4).

Table 2

Question: Do you or your acquaintances have a history of chemical eye injury?

\begin{tabular}{|lll|}
\hline & Frequency & Percent \\
\hline Yes (self) & 74 & 8.3 \\
\hline Yes (close friend or family member) & 64 & 7.2 \\
\hline No & 750 & 84.5 \\
\hline Total & 888 & 100 \\
\hline
\end{tabular}

A total of 399 (44.9\%) respondents selected "not applicable" or "other," because they were either students or did not have a job, or because of the nature of their work. In our study, $72(8.1 \%)$ respondents had a history of chemical eye injury, including minor food-related injury, such as hot sauce or cooking oil splash. Moreover, 64 (7.2\%) respondents had a close friend or family member who experienced a chemical eye injury, including minor food-related injury (Table 2).

Knowledge related to chemical eye injuries 
Table 3

Answers to questions and statements testing the knowledge related to chemical eye injuries

\section{Statement: chemical injury can cause ocular complications}

\begin{tabular}{|lll|}
\hline & Frequency & Percent \\
\hline Agree & 784 & 88.3 \\
\hline Disagree & 14 & 1.6 \\
\hline Don't know & 90 & 10.1 \\
\hline Total & 888 & 100.0 \\
\hline Question: what should be the first corrective action when a chemical injury occurs? \\
\hline & Frequency & Percent \\
\hline Wash with plenty of water & 655 & 73.8 \\
\hline Wash with little of water & 42 & 4.7 \\
\hline Cover the eye & 5 & 0.6 \\
\hline Go to Emergency Department & 164 & 18.5 \\
\hline Pharmacy and Eye Drops & 11 & 1.2 \\
\hline Other & 11 & 1.2 \\
\hline Total & 888 & 100.0 \\
\hline Statement: alkaline injuries are more dangerous than acidic injuries & \\
\hline & Frequency & Percent \\
\hline Agree & 491 & 55.3 \\
\hline Disagree & 140.6 & 15.8 \\
\hline Don't Know & 257 & 28.9 \\
\hline Total & 888 & 100.0 \\
\hline Statement: locate and remove particles in the eye in case of chemical injury & Frequency & 62.2 \\
\hline & 552 & 17.2 \\
\hline Don't know & 153 & \\
\hline
\end{tabular}




\begin{tabular}{|lcc|}
\hline \multicolumn{4}{|l|}{ Statement: chemical injury can cause ocular complications } \\
\hline Total & \multicolumn{3}{l|}{} & \multicolumn{2}{l|}{} \\
\hline \multicolumn{4}{|l|}{ Statement: when injured with acidic } & 100.0 \\
\hline & Frequency & Percent \\
\hline Agree & 75 & 8.4 \\
\hline Disagree & 353 & 39.8 \\
\hline Don't know & 460 & 51.8 \\
\hline Total & 888 & 100.0 \\
\hline Statement: when injured with alkaline material, & wash with acid solution \\
\hline & Frequency & Percent \\
\hline Agree & 60 & 6.8 \\
\hline Disagree & 404 & 45.5 \\
\hline Don't know & 424 & 47.7 \\
\hline Total & 888 & 100.0 \\
\hline
\end{tabular}

In total, 784 (88.3\%) respondents agreed that chemical substances can cause eye complications (Table 3). Regarding the first corrective action in case of chemical eye injury, majority of the respondents $(697,78.5 \%)$ said that washing the eye with water should be the first action; of these 697 respondents, $655(73.8 \%)$ said that washing the eye with plenty of water should be performed, and $42(4.7 \%)$ said that washing the eye with little water was appropriate. In contrast, $164(18.5 \%)$ respondents said that going to the emergency department should be the first corrective action (Table 3 ).

Regarding whether alkaline injuries are more dangerous than acidic injuries, 491 (55.3\%) respondents agreed, 140 (15.8\%) disagreed, and 257 (28.9\%) did not know (Table 3). Regarding whether particles should be located and removed in case of chemical injury, 552 (62.2\%) respondents agreed (Table 3$)$. Regarding whether an eye injured with an acidic substance should be washed with an alkaline solution, 75 (8.4\%) respondents agreed, 353 (39.8\%) disagreed, and 460 (51.8\%) did not know (Table 3). Regarding whether an eye injured with an alkaline substance should be washed with an acidic solution, 60 (6.8\%) respondents agreed, 404 (45.5\%) disagreed, and 424 (47.7\%) did not know (Table 3).

\section{Discussion}

Vision is one of the most important human functions. Loss of vision from chemical injury may greatly affect quality of life. This study aimed to assess the knowledge of immediate corrective action in cases of chemical eye injury, among individuals in the Saudi community, in order to reduce the incidence of 
ocular injuries and related complications. When our participants were asked whether chemical substances can cause eye complications, we found that $88.3 \%$ agreed; this is consistent with the findings of another study conducted among Latino farm workers, where $97.3 \%$ agreed that wind, dust, and chemicals could cause eye problems [8].

In cases of chemical ocular injuries, rapid irrigation and dilution of the chemical with water should be the immediate first corrective action, in order to reduce tissue damage and protect vision $[9,10]$. In our study, $78.5 \%$ of the respondents indicated that washing the eyes with water should be the first corrective action. However, $8.4 \%$ of respondents in our study indicated that in cases of acidic eye injuries, the eyes should be washed with an alkaline solution, which is extremely dangerous; moreover, $6.8 \%$ indicated the opposite washing regimen, that eyes should be washed with an acidic solution in cases of alkaline eye injuries, which is also dangerous. Approximately $50 \%$ of our respondents did not know that both the washing regimens could be dangerous and therefore, should not be considered at all.

The severity of ocular injury is related to the type of chemical, the volume and $\mathrm{pH}$ (alkaline or acidic) of the solution, and the duration of exposure. Notably, alkaline solutions penetrate more rapidly into the eye, relative to acids; therefore, alkaline solutions are more damaging to intraocular structures such as the iris, lens, and ciliary body, resulting in rapid and irreversible damage [11]. In our study, 55.3\% of the respondents agreed that alkaline eye injuries were more dangerous than acidic eye injuries. After ocular chemical injury, it is important to search for and remove solid particles that could be trapped in the conjunctival fornices and act as reservoir for continued chemical release and inflammation [6, 9]. This was recognized by $62.2 \%$ of the respondents in our study, who agreed that particles should be located and removed in case of chemical eye injury.

\section{Conclusion}

The eye is an important, irreplaceable organ. Loss of vision through ocular chemical injury is a serious condition that can negatively affect quality of life, primarily through job loss and increased dependence on others. Our findings indicate that individuals in the Saudi population need greater awareness regarding immediate corrective action in cases of ocular chemical injuries. Furthermore, there is a need to clearly communicate that water should be the only solution used to irrigate the eye; no other solutions should be used, regardless of $\mathrm{pH}$. Expansion of these results should be performed by health authorities, in conjunction with the development of appropriate interventions, such as health awareness campaigns regarding ocular chemical injuries and immediate corrective actions, in order to improve knowledge and to create a healthier society.

\section{Limitations}


The primary limitation to the generalization of these results is the selection bias. We used an electronic questionnaire for our study; therefore, the results are subject to the bias that people with higher level of education (that could answer the questionnaire) were included. Future studies are needed that should include a wider section of population irrespective of the level of education.

\section{Declarations}

\section{Ethics approval and informed consent}

Written informed consent was obtained from all participants. The study was approved by the Biomedical Ethics Committee at King Abdulaziz University, and was conducted in accordance with the ethical standards of the Declaration of Helsinki.

\section{Consent for publication}

Not applicable.

\section{Availability of data and materials}

The data are not available for public access because of privacy concerns; however, these could be obtained from the corresponding author on reasonable request.

\section{Competing interests}

The authors declare that they have no competing interests.

\section{Funding}

This research received no specific grant from any funding agency in the public, commercial, or not-forprofit sectors.

\section{Authors' contributions}

Dr. Ahmed Basheikh conceived the original idea, was involved in planning, and supervised the work. All authors contributed to the design and implementation of the research. They also contributed to the analysis and interpretation of the results. Furthermore, they all discussed the results and commented on the final manuscript.

\section{Acknowledgements}


None

\section{References}

1. Belkin M. Ocular war injuries in the Yom Kippur war. J Ocul Ther Surg. 1983;2:40-49.

2. Gombos GM. Ocular war injuries in Jerusalem: During the 1967 Arab-Israeli conflict. Am J Ophthalmol. 1969;68:474-8.

3. Négrel A-D, Thylefors B. The global impact of eye injuries. Ophthal Epidemiol. 1998;5:143-69.

4. Pargament JM, Armenia J, Nerad JA. Physical and chemical injuries to eyes and eyelids. Clin Dermatol. 2015;33:234-7.

5. Xiang H, Stallones L, Chen G, Smith GA. Work-related eye injuries treated in hospital emergency departments in the US. Am J Industr Med. 2005;48:57-62.

6. Morgan SJ. Chemical burns of the eye: causes and management. Br J Ophthalmol. 1987;71:854-7.

7. Pitkanen J, Al-Qattan MM. Epidemiology of domestic chemical burns in Saudi Arabia. Burns. 2001;27:376-8.

8. Verma A, Schulz MR, Quandt SA, Robinson EN, Grzywacz JG, Chen H, et al. Eye health and safety among Latino farmworkers. J Agromed. 2011;16:143-52.

9. Kosoko A, Vu Q, Kosoko-Lasaki O. Chemical ocular burns: a case review. Am J Clin Med. 2009;6:41.

10. Seimon R. Preventing blindness from eye injuries through health education. Community Eye Health. 2005;18:106.

11. Kuckelkorn R, Schrage N, Keller G, Redbrake C. Emergency treatment of chemical and thermal eye burns. Acta Ophthalmol Scand. 2002;80:4-10.

\section{Supplementary Files}

This is a list of supplementary files associated with this preprint. Click to download.

- Additionalfile1.docx

- Additionalfile2.docx

- Additionalfile4.docx

- Additionalfile3.docx 